\title{
Customer Relationship Management in the Technology Era
}

\author{
PhD candidate. Aurora Binjaku \\ Prof. Assoc. Dr. Tamara Luarasi \\ Prof. Assoc. Dr. Hysen Binjaku
}

aurora.binjaku@digitalb.tv, tamara.luarasi@uet.edu.al, hysen.binjaku@uet.edu.al

\section{Doi:10.5901/ajis.2014.v3n1p325}

\section{Abstract}

Our economy is developing very fast. Business must undertake several strategies to accomplish their customers' requirements and to increase their revenues. Many companies are recognizing enterprise data as a strategic business asset. This information is core material to future marketing, sales, purchase and business strategies. Before a data strategy must be driven the company should have a clear situation of the processes that generate information that is necessary to know and to be studied. We take in consideration very close data for the customer. We will study this kind of information, specifically for a pay television that operates in Albania. We will study the customer relationship management as a new method which is used last years and that has as objective the creation of a close relation between business and customers. Specifically, we will take in consideration the major data that a pay television needs to have to undertake efficient strategies plans. For this, we can make use of information technology specifically mobile applications and Cloud Computing. Customers can record the data that can later be processed and is used by managerial levels. This paper is about the new information technologies implementations by making use of mobile telecommunication technology specifically the mobile phone devices such as Android and the integration with Google Cloud Technologies. We aim to give a real solution for all the companies regarding the customer interaction by making use of new technologies. To reach our goal we have taken into account a business scenario, based in an Albanian company. Author's experience in information and management fields and the foreign authors' studies is core to reach the conclusion. At the end, we have come to some conclusions hoping that we have gone a step forward and have contributed in this matter.

Keywords: CRM, cloud computing, mobile applications, database, business strategies

\section{Introduction}

Our economy is developing very fast. Business must undertake several strategies to accomplish their customers' requirements and to increase the sales. Many companies are recognizing enterprise data as a strategic business asset (Paul Barth 2013). Companies that are quoted in the stock market are obliged to disclose their financial reports so the potential investors can evaluate the financial situation of the company where they want to invest. Beside the fact that financial reports disclosure is imposed by law, companies have the need to generate financial or non financial reports for their activities. Despite financial report companies must record other useful data that comes from their everyday working process or that are generated from different business relations (Barnaby Page 2010). This information is core material to future marketing, purchase or sales strategies. Before a data strategy must be driven the company should have a clear situation of the processes that generate information that is necessary to know and to be studied. After that there must be an answer to the questions "what are the data that should be studied?" and "how will the company capture the data?" (Crmtrend.com).

Nowadays, there are several ways for a company to retrieve information for the business environment where it operates. They may contract marketing agencies to study the market or customer behavior, to evaluate certain investment plans or to do the promotion strategy. Also, there are several software where data can be recorded and some results are shown. The point in the overall is to decide first the kind of information that adds value to the business.

Information can be gathered for a company's purchase environment. By having total information of the suppliers or partners the company can choose among several purchasing strategies to achieve cost effectiveness and to compete in the market. Information regarding the environment where the company is operating or wants to enter is also important. This information includes social, economic, legislative, macroeconomic data. Depending on the information the company 
can decide whether or not to enter the market in an environment or to undertake certain business strategies. Very important is the information regarding the customers. Here we do not rely only for their likes and dislikes regarding the products. We take in consideration very close data for the customer. We will study this kind of information, specifically for a pay television that operates in Albania. Our country is still under developing stage that adheres to be a European Community candidate.

\section{Pay TV Platforms in Albania (A. Binjaku 2011)}

Pay TV platforms are private companies, which offer for a certain price various television channels in a single package. They do not offer only television channels but technology as well. The television package contains programs, productions, and interactive services, all through an encoded digital transmission.

In Europe the first companies date at years ' 80 , while in Albania the first platform, not with its own production, was created on year 2003, which offered only sports program. At 2004, the first genuine company begins its activity, which offered its own production by payment. This company named Digitalb Sh.A. has its activity still going on nowadays and is a leader in the Albanian market. At 2008 another company named Tring TV joins the market and it is facing market consolidation too.

Beside television services offered by both companies, Digitalbsha for being more competitive offers in its package other services as:

- PPV (Pay Per View)-the subscriber pays only for the desired program

- HD (High Definition)- high quality television transmission. This is offered in some of its own channels and in other international channels.

- PVoD (Push Video on Demand, on testing process and actually free of charge)- the subscriber will have a library with a wide programming range and can choose anytime the desired program by paying a fee.

Home companies have expanded their target market by offering their services in the region countries as Kosovo, Macedonia, Montenegro, Greece and Europe.

\section{Customer Relationship Management}

Customer relationship management came up by Siebel Systems, an IT company in 1993 (Crmtrends.com). After some difficult years, now it has been returned stronger and effective for very big companies. CRM means to know the customers very close, to have knowledge regarding their desires, purchasing history, likes and dislikes. For the company CRM means to be present and to assist the customers every moment in every possible way, to process the gathered data in order to undertake business strategies for being competitive and to raise their earnings. For better understanding we will use the common phrase "to have a 360 grade view" for the customer. CRM helps to improve the relation with the customers, to create an emotional relation and the former can feel that the company is there for him, listens to him and does everything to achieve his satisfaction. There are several ways to achieve the customer loyalty (crmtrends.com). The company must offer some ways how to communicate with the customer despite the relation with the broker. Nowadays, social media is a very used term that relies to the latest methods how a company can reach its clients. Facebook, Twitter, Youtube, self webpageetc are the modernized Medias where both parties can meet and interact. CRM also offers different ways of offering customer care and help desk service. Despite interactivity communication companies still must take in mind that the marketing strategies regarding the products and market segmentation are not yet old methods. The company can use CRM to gather the needed information regarding their customers in order to undertake the right strategies.

There are several companies that offer CRM software and the market is increasing very fast. In this paper a case study will come to help for understanding the importance of the new strategies that companies may undertake for increasing their revenues.

Pay televisions have a more complex information database regarding their customers. These platforms offer television channels in several packages by payment. Their customers are the subscribers that buy the products and watch several channels with different themes. Audience measurement is a way that the platform can use to know its customers favorite thematic and the hours when they use the product. By making use of this information the platform can undertake strategic plans for their program. But it is a great difference between what they watch and what they desire to watch. The company must know its customers preferences. The company has the need to know the audience, the potential clients, and preferences too. Processing the preferences data the company can undertake significant strategies 
regarding the channels organization, the program categories, and the material type.

CRM software in pay television offers the monthly billing service despite the other services.

Coming back to our platform we have taken in consideration some information that is significant for the company and that can be used for strategic marketing plans. The company can have the following information from its customers and not-consumers:

First data category-general information for marketing strategies:

- Where is the customer house (city, village, urban, rural environment)

- Family's overall revenues

- Number of the residents in the house (grown up and children)

- User/ not user/ Ex user

- If an Ex user: Why did the customer move to a different platform

- If not a user: Why does not subscribe to pay television

Second data category-information regarding their preferences, likes and opinion for program and business strategies:

- Preferences for the program category, movies thematic, watching hours

- Preferences for the channel material organization and on demand services

- The opinion for several offered services

- The opinion regarding the company, etc.

These records can be processed in a chart type or in a complex table that can give all the information needed to make decisions.

The incentive to fill the data in the application:

There are several ways how to promote and give an incentive to everyone to fill the data. For example, free days of television signals can be offered for the users, free mobile communication minutes (in partnership with the mobile operators) for the not users and Ex users.

The methodology how information will be gathered:

The answers will be filled by every person who has a smart phone, internet connection, and have downloaded the mobile application. Table 1 shows the modest view that the application will have once the customers record their data.

Table 1: The mobile phone application views

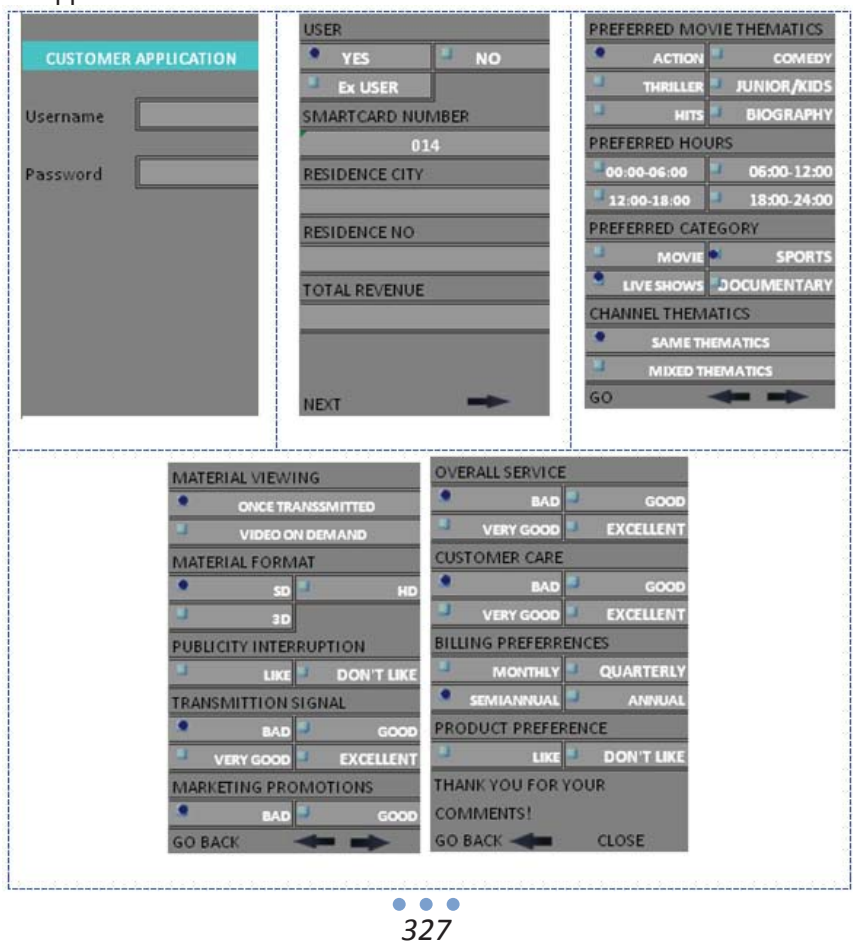


The following diagram shows the steps how the information will be gathered, how will be saved, translated in a customer database and finally be processed and used to undertake marketing, sales or business strategies. Once all the data are submitted, they will be recorded in a database in the Cloud. Further on we will explain the reason why we have chosen these technologies. In this point, it is important to say that CRM strategy and the data should be defined carefully because they should sustain the main strategies (Crmtrends.com).

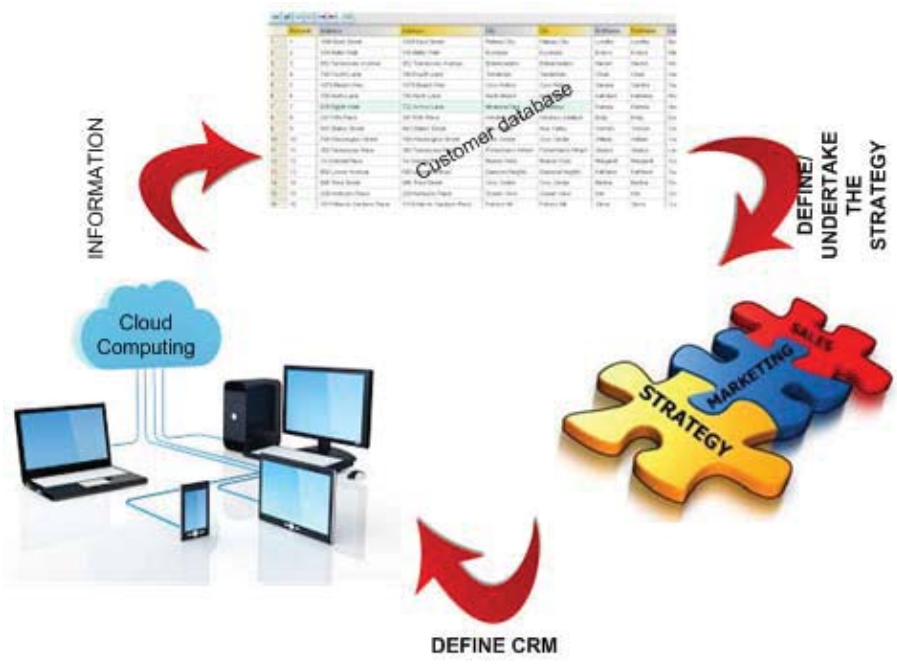

Our aim is to give substantial information to the platform that will be used to evaluate the best marketing policies and business strategies regarding the product that it offers. A marketing strategy is the segmentation of the market based on the financial revenues either the entered market or the potential one. In certain environments where the products are not sold the platform can undertake a different strategy regarding the packages that offers. Business strategies are long-term policies, necessary to be taken for improving the company's performance in the overall activity. In our case we refer to program, technical, customer care strategies. Despite the fact that programming and technical division play a key role in the final product.

Our platform has more than 250,000 subscribers and it would have a high cost to phone or meet every client. This is the reason why we meet new technologies for this process implementation. The questionnaire can be filled even in the platform's webpage so the number of the answers can be larger. Furthermore, we will use cloud computing where the gathered data will be saved. Cloud computing is a new technology that allows users to process data over the internet in real time. We find some of the advantages of the Cloud environment that Zaigaham Mahmood and Richar Hill have mentioned on "Cloud Computing for Enterprise Architecture" very appropriate for our company like:

- Optimization of the company's capital investment by reducing cost of the purchasing hardware and software, resulting in a much lower total cost of ownership and, ultimately, a whole new way of looking at the economics scale and operational IT.

- Providing novel and complex computing architecture and innovation potential.

Beside them we consider the Cloud environment use a very secure method, helping the company does not have information flow risks.

The company already has a database where every subscription for every customer is recorded, the common view is shown on Table 2.

Table 2: The database for marketing strategies reasons

\begin{tabular}{|cccccccc|}
\hline Smart Card & Customer & User & Pay TV User & Ex User & City/region & No of residents & Total Revenue $€$ \\
\hline $01422 \times x \times 01$ & A.B & Yes & No & No & Tirana & 5 & 1,000 \\
\hline $01423 \times x \times 89$ & C.D & No & Yes & Yes & Durres & 6 & 800 \\
\hline N/A & E.F. & No & No & No & Kruja & 8 & 900 \\
\hline & & & 328 & & & \\
\end{tabular}


So the company already has the customers purchasing history. The customer is recognized by the smart card number. For this reason to our users and ex users will be asked to record their smart card number. By having a common field we can link all the information gathered for the customer, his purchasing history and the recorded data by our application. Table 3 shows a database report of the customers' information that meets both sales history and personal data.

Table 3: Extended customers' database view for marketing reasons/linked records

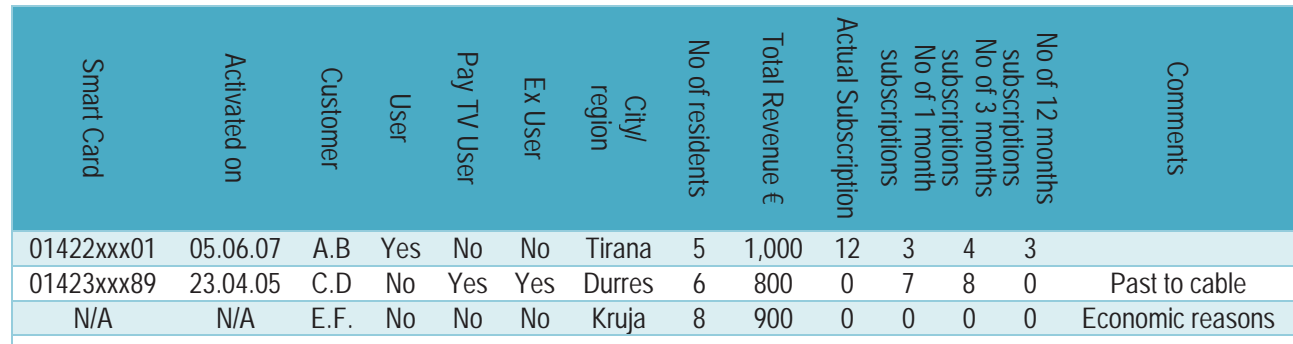

Other information can be asked to be filled but sometimes using these applications may be difficult to be used from a smart phone. Anyway the application can be adapted to new requests that the company may have. An important step is to know in advance the reason why these data are needed, how will be used and to achieve which objective.

All the recorded data will be gathered in a database. The data will be processed and the final product will be a table where all the necessary information is shown this table then can be used by the managers for the future policies. For some reasons, mainly for security reasons, this database cannot be saved in the same server where the company's software are settled. This database has high consulting and updating frequency and a server base cannot allow happening in its environment.

\section{Technical Aspects}

As we mentioned, beside the financial data stored in company server, there are a lot of data regarding the costumer information and the customer opinion. These data have to be updated frequently every day and we need to provide daily information about them, like the report in the Table 3. For this reason we have thought that another database would be appropriate to maintain these data and we have concluded to use a cloud database. The cloud database provokes the integration of other cloud technologies. The Google Cloud Platform is proposed in this study and for this reason all the other technologies are part of Google Cloud Framework. This work involves two aspects: the Google Console aspect and the programming aspect.

From Google Console we create a project and define some settings for this project by a Wizard. Two components are defined for this project: a Google App Engine component

(https://developers.google.com/appengine/downloads\#Google_App_Engine_SDK_for_Java), and a Google Cloud SQL component (https://developers.google.com/cloud-sql/?hl=it-IT). The last one includes in his configuration the Google App Engine Component identification.

On the other side, on the development environment, which is the Eclipse in our case, some other configurations are done to be connected with the Google project components and Google API.In Eclipse we have included first of all the Google plugins, which make possible the development of a Google web application which is part of Google App Engine. The servlet technology is used. A configuration is done to be connected with Google App Engine Component ID, using the property option of the Eclipse project. At the beginning we connect the web application with a local MySQL database, and for this we make a specific configuration of the project using the property. Inside the application the connection with the local database is provided by:

\section{Class.forName("com.mysql.jdbc.Driver")url = "jdbc:mysql://127.0.0.1:3306/database_name?user=root";}

The testing process includes the running of the application in Eclipse as a web application, and from the browser we use the address http://localhost:8888/googleproject, where googleproject is the name that identifies our servlet in the web.xml file in our project. When we have tested everything with a local database, we replace the connection with a local 
database with the connection with a Cloud MySQL database. Meanwhile, the Google Cloud SQL instance console gives us the possibility to create our conceited database, which was tested locally. Inside the code the connection will be as follows:

Class.forName("com.mysql.jdbc.GoogleDriver");

url= "jdbc:google:mysql://project-ID:

SQL-component-ID/database_name?user=root";

Where project-ID is the project identification on Google side, and SQL-component-ID is the identification of Cloud SQL component on Google site too. From this moment we are able to deploy our web application in Google and this means that we can use now our application from browser with a URL address that Google provides us in the moment of the Google App Engine component creation.

All this process provides the web application which can be considered now as a Google service and make us able to use a Cloud database for which we are interested.

There are different ways of using service. We can use it with a URL address as we mentioned above, or by a smart-phone. The second one is very much required today as we all know. Therefore, part of the technical aspect of the study is the Android Application that we consider to be used by the users and by employees.

There are some key points that we have considered in our Android application. We worked in Eclipse for this application too. The Google authentication makes the application able to use the Google services. To provide the knowledge about our application to Google and to provide its authorization we need again to work on both sides: on Google Console and on programming side. On the Google Console we define a new project and some settings for this project, like OAuth 2.0 Client ID, the type of the application, and in our case we have the installation application type, we put the package name of our Eclipse project, and the fingerprint of our application to Google. We are not intended to give here details for the steps of this process.

On the programming side we have use the class Activity and some interfaces like ConnectionCallbacks, OnConnectionFailedListener, OnClickListener,OnAccessRevokedListenerand the class PlusClient to activate the implementations of the interface methods.

(https://gist.github.com/ianbarber/5170508;http://www.riskcompletefailure.com/2013/03/common-problems-withgoogle-sign-in-on.html)

Another key point of the Android application is the use of the AsyncTask class, which makes possible the activation of the Google web application that we did, from Android application.

Finally the task of the Android Application is the creation of the series of the screens that are presented in the Table 1.

\section{Conclusions}

Customer relationship management is a new tool that raises the business performance by creating client loyalty.Companies need several data to decide for the strategic policies.

These data have to be not part of the database that the company has with its principal financial data. The reason is the frequent use of them, and It is not likely for the IT system people to have these kind of data in the same database with the financial data. them.

A Cloud database is a very good solution to separate these categories of data and define different ways of use for

In our study we have used the Google platform and an integration of its different components. AGoogle web Application, is created, which will play the role of a Google service that will provide the connection with the database.

The use of this service can be done in different ways. The study has considered the use of this service from the smart-phone, which is achieved by an Android application.

The use of the smart phone will collect easier the information from the customer in two aspects: more information and less cost for this process.

On this paper we presented the implementation of a business scenario by making use of an Android Application and Google Cloud Platform. Severe data can be uploaded by users. Data are automatically upgraded to a central database in Cloud and then be processed and arranged to have the necessary information for managers to decide for future strategies. 


\section{References}

Zaidham Mahmood Richard Hill, "Cloud Computing for Enterprise Architectures 2011.

https://developers.google.com/appengine/downloads\#Google_App_Engine_SDK_for_Java

https://developers.google.com/cloud-sql/?hl=it-IT

https://gist.github.com/ianbarber/5170508

http://www.riskcompletefailure.com/2013/03/common-problems-with-google-sign-in-on.html

https://data.worldbank.org/about/country-classifications/country-and-lending-groups

http://www.gartner.com/newsroom/id/2613015

http://www.businessweek.com/news/2011-12-07/sap-challenges-oracle-with-3-4-billion-successfactors-purchase.html

https://enterpriseapptoday.com/crm/top-5-crm-trends-for-2013.html

[3][5] http://www.crmtrends.com/crm.html

http://forbes.com/sites/microsoft/2011/01/11/4-business-benefits-of-cloud-management-technology

www.crm.com

www.digitalb.al

[1] "Turning big data into useful information" Quinstreet storage ebooks. 2013

[2] Page, B. (2010) "Cloud Computing, a guide for business managers". The Faculty of Information Technology of the Institute of Chartered Accountants in England and Wales ISBN 978-0-85760-000-4

[4] Binjaku, A. (2011) "Analiza e efektivitetit ekonomik dhe financiar e sektorit televiziv me pagese" Mikroteze Universiteti Europian I Tiranes

D. Jason, G. Vijay, L. K. Keneth "Information Technology and Economic performance: A Critical Review of the Empirical Evidence"University of California, Irvine ACM Computing Surveys, Vol. 35, No. 1, March 2003, pp. 1-28.

Deloitte (2005) "Why information technology controls can't be ignored CEO/CFO" Certification News May 2005 
